\title{
Extra Corporeal Membrane Oxygenation (ECMO)
}

\author{
Khalid Monzer MD
}

\section{INTRODUCTION}

ECMO (Extra corporeal membrane oxygenation) is a blood circuit outside the body which provides $\mathrm{O}_{2}$ and removes $\mathrm{CO}_{2}$. It is a management option for patients with severe respiratory failure since theoretically it allows the lungs to recover while avoiding harmful measures like high pressure ventilation and high fractional inspired oxygen $\left(\mathrm{FiO}_{2}\right)$. Practically, ECMO is complicated and costly, needs resources, and has the potential for grave complications. Clear clinical evidence that demonstrates a beneficial effect of ECMO in severe acute respiratory failure is lacking. With advancement in techniques and technology, ${ }^{1,2,}$ the interest in ECMO has increased in recent years, in part due to the H1N1 pandemic. ${ }^{4}$ This article provides a brief introduction about the use of ECMO in adult respiratory failure.

\section{MECHANICS}

\section{Venovenous (VV- ECMO) (Figure 1)}

Right atrial venous blood is drained through a large cannula from one or both vena cavae and pumped through an artificial lung and back into the right atrium. VV- ECMO puts the artificial lung in series with the native lung. It is usually the technique used in adult respiratory failure unless the patient has overt cardiac failure or refractory shock. Complications like systemic thromboembolism and limb ischemia are lower in VV- ECMO. It also preserves pulmonary blood flow, pulsatile systemic flow, and oxygenation of blood in the left ventricle and aortic root.

Corresponding author: Khalid Monzer MD Contact Information: Khalid.monzer@ttuhsc.edu DOI: 10.12746/swrccc2014.0207.084

\section{Venoarterial (VA- ECMO) (Figure 2)}

Venous blood is drained from the right atrium, oxygenated, and returned to the aorta (usually to the femoral artery). It is an effective system to provide support for patients with cardiogenic shock refractory to treatment. It has been successfully used as a bridge to myocardial recovery, VAD implantation, and cardiac transplantation.

\section{Arteriovenous (AV-ECMO)}

It is used for extracorporeal $\mathrm{CO}_{2}$ removal (ECCOR) and requires low blood flow to the circuit to remove $\mathrm{CO}_{2}$, while the patient is oxygenated by conventional methods with mechanical ventilation.

\section{ECOM Circuit}

The ECMO circuit consists of an oxygenator, a pump, a heat exchanger, and cannulas and tubing. Modern oxygenators, coated with polymethylpentene, cause less platelet consumption, have a lower resistance to blood flow, and have more effective gas exchange. $\mathrm{CO}_{2}$ clearance is determined by fresh gas flow into the circuit. Increasing gas flow above a certain level does not improve $\mathrm{PO}_{2}$. Effective $\mathrm{CO}_{2}$ clearance is reached with blood flow as little as $10-15 \mathrm{ml} /$ $\mathrm{kg} /$ minute. Effective oxygenation usually requires at least $50-60 \mathrm{ml} / \mathrm{kg} /$ minute. Gas flow into the system is usually $100 \% \mathrm{O}_{2}$.

\footnotetext{
Author Affiliation: Khalid Monzer is a fellow in pulmonary and critical care medicine in the Department of Internal Medicine at TTUHSC in Lubbock, TX.

Received: 04/19/2014

Accepted: 07/08/2014

Reviewers: Victor Test MD

Published electronically: 07/15/2014

Conflict of Interest Disclosures: none
} 


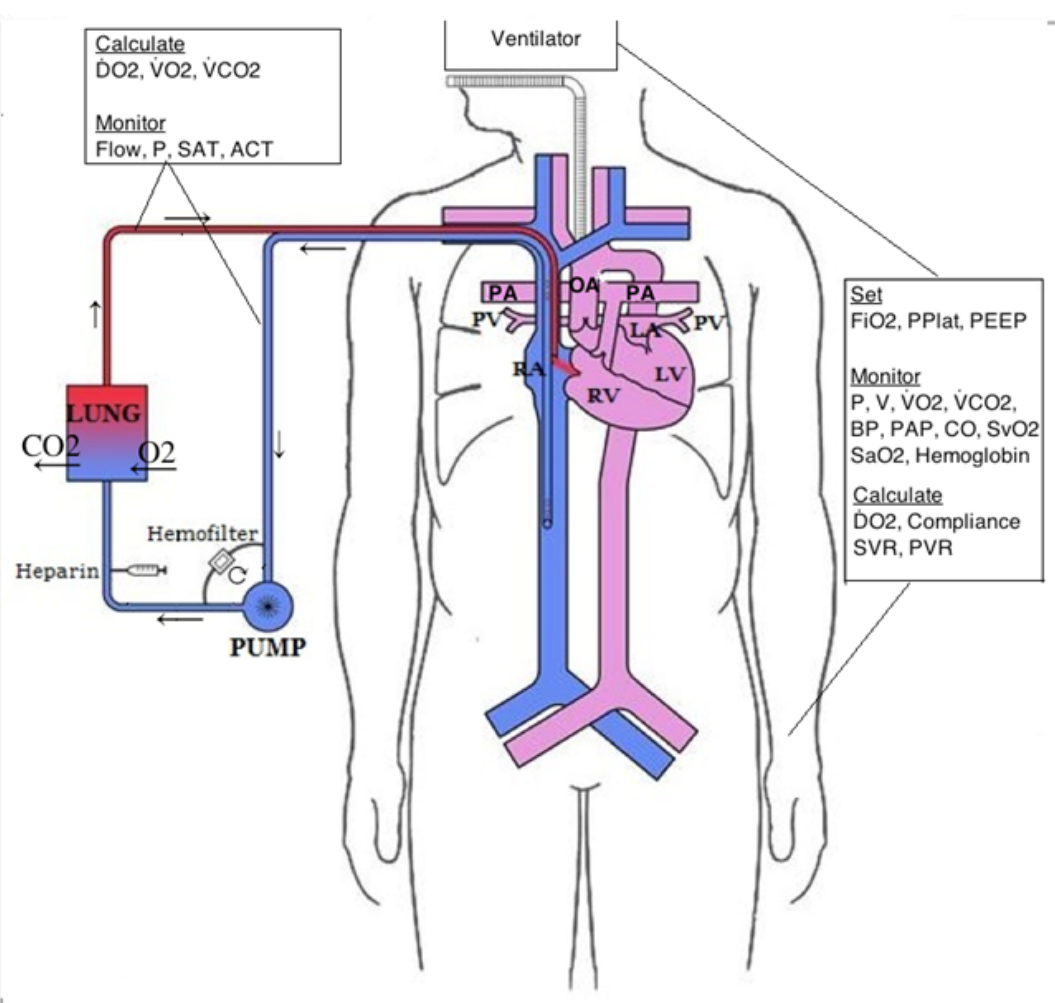

Figure 1:

Venovenous ECMO with bicaval drainage. $\mathrm{FiO}_{2}$ fractional inspired oxygen, Pplat plateau airway pressure, $P E E P$ positive end-expiratory pressure, $P$ pressure, $V$ volume, $V O 2$ oxygen uptake, $\mathrm{VCO} 2$ carbon dioxide uptake, $D O 2$ oxygen delivery, $S V R$ systemic vascular resistance, $P V R$ pulmonary vascular resistance, $B P$ blood pressure, $P A P$ pulmonary artery pressure, $\mathrm{CO}$ cardiac output, $\mathrm{SvO} 2$ mixed venous oxygen saturation, $\mathrm{SaO} 2$ arterial oxygen saturation, Sat saturation, $A C T$ activated clotting time, $\mathrm{CO} 2$ carbon dioxide, $\mathrm{O} 2$ oxygen

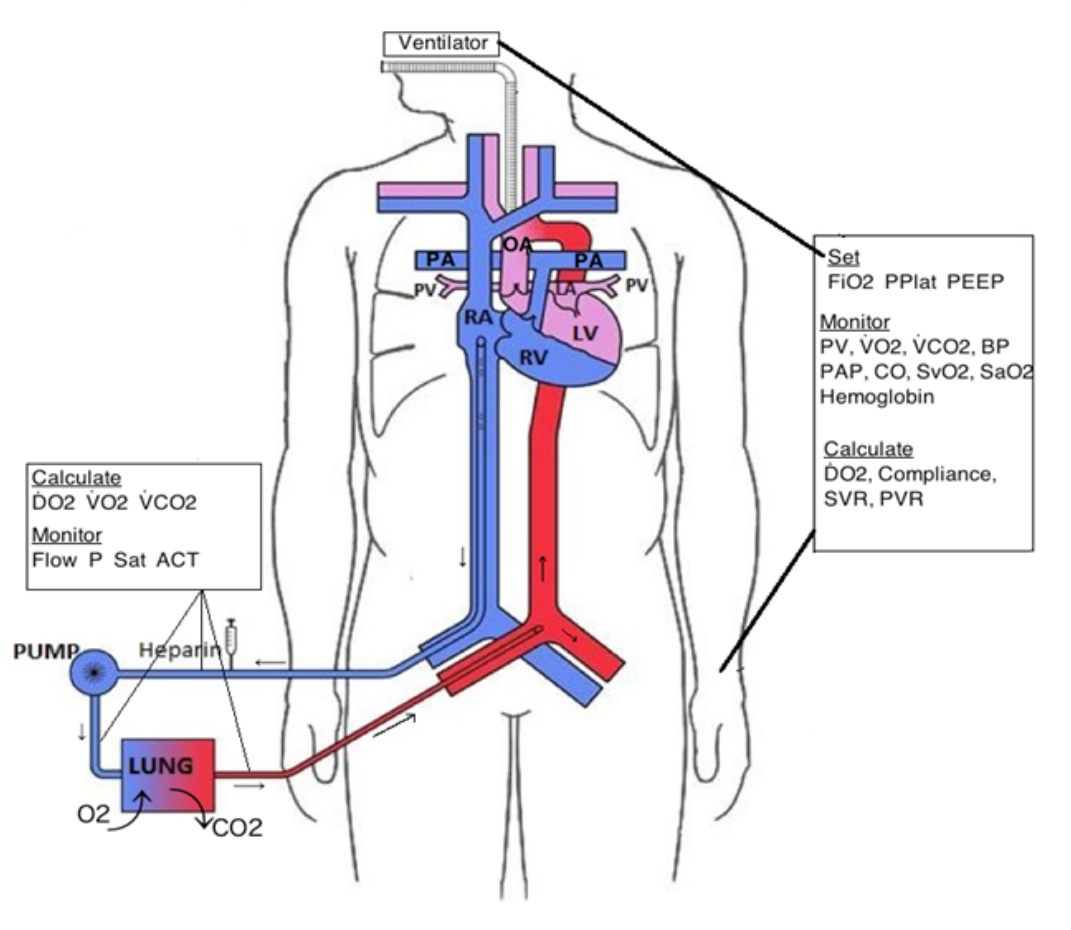

Figure 2:

Venoarterial ECMO with femoral- femoral access. FiO2 fractional inspired oxygen, Pplat plateau airway pressure, $P E E P$ positive end-expiratory pressure, $P$ pressure, $V$ volume, $\mathrm{VO} 2$ oxygen uptake, $\mathrm{VCO} 2$ carbon dioxide uptake, DO2 oxygen delivery, $S V R$ systemic vascular resistance, $P V R$ pulmonary vascular resistance, $B P$ blood pressure, $P A P$ pulmonary artery pressure, $\mathrm{CO}$ cardiac output, $\mathrm{SvO} 2$ mixed venous oxygen saturation, $\mathrm{SaO} 2$ arterial oxygen saturation, $\mathrm{Sat}$ saturation, $A C T$ activated clotting time, $\mathrm{CO} 2$ carbon dioxide, $\mathrm{O} 2$ oxygen 


\section{Patient management}

\section{Indications}

There is no clear set of indications for ECMO in severe adult respiratory failure. Some have proposed a mortality rate higher than $80 \%$ with conventional standard of care as a general indication to use ECMO ${ }^{8,10}$ However, determination of patient mortality is not easy in most cases. Below is a table showing indications used in some recent ECMO trials. bocytopenia; the newer devices have lower affinity to platelets. The usual practice is to keep platelets $>80,000 / \mu \mathrm{L}$. Platelets less than $20,000 /$ $\mu \mathrm{L}$ are associated with spontaneous bleeding.

4. Body temperature: This is controlled by the heat exchanger; patients on ECMO should not have overt fever.

5. Sedation: In VV-ECMO, sedation is used to facilitate mechanical ventilation. During cannulation, the patient should be deeply sedated and

\begin{tabular}{|l|l|}
\hline Title & Indications for ECMO \\
\hline $\begin{array}{l}\mathrm{Zapol} \\
1979^{9}\end{array}$ & $\begin{array}{l}\mathrm{PaO}_{2} / \mathrm{FiO}_{2} \text { ratio }<50 \text { for }>2 \mathrm{~h}, \text { or } \mathrm{PaO}_{2} / \mathrm{FiO}_{2} \text { ratio }<83 \text { with } \mathrm{FiO}_{2}>0.6 \text { and } \mathrm{PEEP} \geq 5 \mathrm{cmH}_{2} \mathrm{O} \text { for }>12 \mathrm{~h}, \\
\text { and intrapulmonary shunt }>30 \% \text { of cardiac output when measured at } \mathrm{FiO}_{2} 1.0 \text { and } \mathrm{PEEP}_{\text {of }} 5 \mathrm{cmH}_{2} \mathrm{O}\end{array}$ \\
\hline $\begin{array}{l}\text { CESAR } \\
2009^{20}\end{array}$ & $\begin{array}{l}\text { Inclusion criteria: age } 18-65, \text { severe but potentially reversible respiratory failure, with } \\
\text { severe respiratory failure defined as a Murray score } \geq 3.0 \text { or uncompensated hypercapnia with } \\
\text { pH }<7.20 . \\
\text { Exclusion criteria: high pressure ventilation (peak pressure }>30 \text { ) or } \mathrm{FiO}_{2}>0.8 \text { for }>7 \text { days. }\end{array}$ \\
\hline $\begin{array}{l}\text { ELSO guidelines } \\
2009^{11}\end{array}$ & $\begin{array}{l}\mathrm{PaO}_{2} / \mathrm{FiO}_{2} \text { ratio }<80 \text { with } \mathrm{FiO} \mathrm{O}_{2} \geq 0.9 \text { and Murray score 3-4, or } \mathrm{CO}_{2} \text { retention with } \mathrm{PaCO}_{2}>80 \mathrm{mmHg} \text { or } \\
\text { inability to achieve adequate ventilation with Pplat } \leq 30 \text { cmH } \mathrm{O}_{2} \text {, or severe air leak syndromes }\end{array}$ \\
\hline $\begin{array}{l}\text { ANZ ECMO } \\
2009^{4}\end{array}$ & $\begin{array}{l}68 \text { patients placed on ECMO; they all failed advanced mechanical ventilation support and } 80 \% \text { failed } \\
\text { other rescue measures, like prone positioning, inhaled nitric oxide, prostacyclin and } \mathrm{HFOV}_{\text {(median }} \\
\mathrm{pO}_{2} / \mathrm{FiO}_{2} \text { ratio 56, median PEEP 18, and median acute lung injury score 3.8) }\end{array}$ \\
\hline
\end{tabular}

\section{Contraindications ${ }^{10}$}

1. Conditions incompatible with normal life if the patient recovers.

2. Severe coagulopathy.

\section{Practical aspects}

1. Anticoagulation: Patient should be placed on heparin infusion with APTT level target 1.5 times normal range. ${ }^{10}$

2. Hemoglobin: ELSO guidelines recommend normal $\mathrm{Hb}$ level to improve tissue oxygenation. However, some experts accept $\mathrm{Hb}$ between 8-9 $\mathrm{g} / \mathrm{dl}$ if $\mathrm{SaO}_{2}>85 \%$ and there is no active bleeding or acute CAD. ${ }^{10,12}$

3. Platelets: Patients on ECMO often have throm- even paralyzed to prevent spontaneous breathing, which can lead to air embolism. ${ }^{10}$

6. Ventilator management: The patient should be placed on lung protective strategy settings (low $\mathrm{FiO}_{2}$, low plateau pressure, PEEP between 5-15 $\mathrm{cm} \mathrm{H}_{2} \mathrm{O}$ ). No recruitment maneuvers should be attempted. ${ }^{10}$

7. Duration on ECMO: There is no specific time after which ECMO is disconnected for futility. However, the median time observed in some of the observational studies was 10 days. The median time for non-survivors was longer.

8. Cost: One textbook estimated the cost to be around US $\$ 10,000$ per case ${ }^{12,13}$; other investigators estimate higher costs. 


\section{Weaning from $E C M O^{10}$}

VV- ECMO: When the extracorporeal circuit support is lower than $30 \%$, a "trial off" is attempted by simply turning off the $\mathrm{O}_{2}$ flow. If the patient maintains acceptable $\mathrm{SaO}_{2}$ and $\mathrm{pCO}_{2}$ for an hour, decannulation can be done.

AV- ECMO: Trial off during VA access requires clamping of the drainage and infusion blood and adjustment of inotropes and vasopressor doses. Echocardiography is very helpful to assess cardiac function during a trial off. Anti-coagulation is continued during the trial off, and the bloodlines and access cannulas are unclamped periodically to avoid stagnation. If the trial off is successful, circuit lines can be cut and access cannulae "locked" with heparinized saline, awaiting decannulation.

\section{Complications}

Bleeding is the most common complication ${ }^{10}$ and occurs in $10 \%$ to $30 \%$ of patients. It is managed by reducing or discontinuing the heparin infusion, optimizing the native coagulation status, and direct surgical control. Failure of the membrane lung or pump occurs in less than $5 \%$ of patients and is managed by replacing the device. Other uncommon complications are related to cannulation, systemic air embolism, thromboembolism, and infection. In an observational study done in Australia and New Zealand (ANZ ECMO), 14 patients of 68 patients who were placed on ECMO died. Four patients died secondary to bleeding, six patients died secondary to intracranial bleeding, and four patients died with intractable respiratory failure. ${ }^{4}$

\section{LITERATURE REVIEW}

Most of the existing literature on ECMO comes from observational studies. One meta-analysis review article $^{14}$ of ECMO use in the last decade cited 10 observational studies and only one randomized controlled study (CESAR). One early multi-center prospective randomized trail sponsored by the $\mathrm{NIH}$ and published in 1979 compared VA-ECMO versus conventional mechanical ventilation. Ninety patients with severe hypoxemic respiratory failure were entered into a randomized trial. Forty-eight patients were managed using conventional ventilation (including high $\mathrm{FiO}_{2}$ and high pressure), and 42 patients received conventional ventilation and venoarterial ECMO. Survival was low in both treatment arms (9.5\% vs. $8.3 \%)^{9}{ }^{9}$

Morris and colleagues published a trial in 1994 involving 40 patients with severe ARDS. Twenty-one were randomized to $\mathrm{ECMO}$ for $\mathrm{CO}_{2}$ removal plus pressure-controlled inverse ratio ventilation, and 19 were randomized to conventional mechanical ventilation. This study did not show any difference in survival between groups. ${ }^{15}$ After these negative results, enthusiasm for the use of ECMO in adult respiratory failure waned in the 1980s and 1990s.

The University of New Mexico Hospital performed extensive research from 1994-2006 to determine the usefulness of ECMO rescue therapy in Hantavirus cardiopulmonary syndrome (HCPS). Only patients with a projected $100 \%$ mortality rate and with clinical and laboratory evidence of HCPS were eligible to receive ECMO. Remarkably, among the 38 patients who qualified, approximately two thirds survived to recover completely. This result is probably explained by the fact that cardiovascular collapse of the HCPS is profound but uniquely brief. VA-ECMO was used in these patients.

As a consequence of the 2009 influenza A (H1N1) pandemic, the interest in ECMO has increased. In Australia and New Zealand, 68 patients with severe respiratory failure were placed on ECMO, after failing advanced mechanical ventilator support and other rescue therapies, like prone positioning, inhaled nitric oxide, prostacyclin, and high frequency oscillating ventilation. Their median $\mathrm{PO}_{2} / \mathrm{FiO}_{2}$ ratio was 56 , median PEEP was $18 \mathrm{~cm} \mathrm{H}_{2} \mathrm{O}$, and median $\mathrm{ALI}$ score was 3.8 . The mortality rate was $21 \%$ in these patients; bleeding was the most frequent complication. ${ }^{4}$ Subsequently, in the northern hemisphere, many ICUs prepared to use ECMO as an option to face this pandemic. ${ }^{17,18}$ Extracorporeal Life Support 
Organization (ELSO) created an $\mathrm{H} 1 \mathrm{~N} 1$ registry and collected data on 256 cases with a mortality rate of $34 \%$.

CESAR (Conventional Ventilation or ECMO for Severe Adult Respiratory Failure) ${ }^{20}$ was the only controlled clinical trial using modern ECMO technology. In this trial, 180 adults with severe respiratory failure were randomly assigned to continued conventional management or to referral to a specialized center with consideration for treatment with ECMO. Sixty-nine patients in the study arm ultimately underwent ECMO with mechanical ventilation strategy of a low volume, low pressure "resting lung setting." Three patients died before transfer, and 19 patients improved without actually receiving ECMO. A lungprotective ventilation strategy was not mandated in the conventional-management group. The primary outcomes, death or severe disability at six months, occurred in $37 \%$ of the patients referred for consideration for ECMO, as compared to $53 \%$ of patients assigned to conventional management. These results were statistically significant, but they did not take into consideration the subgroup analysis. Patients in the ECMO group probably received better care since they were transferred to a specialized center, and $21 \%$ of them (19/90) improved without receiving ECMO. In conclusion, the study was not a randomized trial of ECMO as compared with standard-of-care mechanical ventilation and had substantial differences in overall care between the study groups.

A prospective study in adult respiratory failure is currently underway in France, the ECMO for Severe Acute Respiratory Distress Syndrome (EOLIA) trial. It is designed to avoid the methodological issues criticized by many in the CESAR study and should be completed in January $2015 .{ }^{21}$

\section{Conclusions}

Even though the new ECMO devices are more efficient, have fewer complications, and cost less, the use of ECMO in adult acute respiratory failure as a treatment option (not as salvage therapy) to provide time for the lungs to heal and to avoid ventilator related lung injury remains controversial. Clear definitive evidence supporting this approach is not available.

\section{REFERENCES}

1. Peek GJ, Killer HM, Reeves R, Sosnowski AW, Firmin RK. Early experience with a polymethyl pentene oxygenator for adult extracorporeal life support. ASAIO J 48:480-482, 2002.

2. Khoshbin E, Roberts N, Harvey C, Machin D, Killer H, Peek GJ, Sosnowski AW, Firmin RK. Poly-methyl pentene oxygenators have improved gas exchange capability and reduced transfusion requirements in adult extracorporeal membrane oxygenation. ASAIO J 51:281-287, 2005.

3. Mendler N, Podechtl F, Feil G, Hiltmann P, Sebening F. Sealless centrifugal blood pump with magnetically suspended rotor: rot-a-flot. Artif Organs 19:620-624, 1995.

4. Davies A, Jones D, Bailey M, Beca J, Bellomo R, Blackwell N, Forrest P, Gattas D, Granger E, Herkes R, Jackson A, McGuinness S, Nair P, Pellegrino V, Pettila V, Plunkett B, Pye R, Torzillo $\mathrm{P}$, Webb S, Wilson M, Ziegenfuss M. Extracorporeal membrane oxygenation for 2009 influenza A (H1N1) acute respiratory distress syndrome. JAMA 302:1888-1895, 2009.

5. Chen YS, Chao A, Yu HY, Ko WJ, Wu IH, Chen RJ, Huang SC, Lin FY, Wang SS Analysis and results of prolonged resuscitation in cardiac arrest patients rescued by extracorporeal membrane oxygenation. J Am Coll Cardiol 41:197-203, 2003.

6. Cove ME, MacLaren G. Clinical review: mechanical circulatory support for cardiogenic shock complicating acute myocardial infarction. Crit Care 14:235, 2010, doi: 10.1186/cc9229.

7. Doll N, Kiaii B, Borger M, Bucerius J, Kramer K, Schmitt DV, Walther T, Mohr FW Five-year results of 219 consecutive patients treated with extracorporeal membrane oxygenation for refractory postoperative cardiogenic shock. Ann Thorac Surg 77:151-157, 2004.

8. Bartlett RH, Gattinoni L. Current status of extracorporeal life support (ECMO) for cardiopulmonary failure. Minerva Anestesiol 76:534-540, 2010.

9. Zapol WM, Snider MT, Hill JD, Fallat RJ, Bartlett RH, Edmunds LH, Morris AH, Peirce EC 2nd, Thomas AN, Proctor HJ, Drinker PA, Pratt PC, Bagniewski A, Miller RG Jr. Extracorporeal membrane oxygenation in severe acute respiratory failure. A randomized prospective study. JAMA 242:2193-2196, 1979 
10. Extracorporeal Life Support Organization ELSO guidelines. http://www.elso.med.umich.edu/WordForms/ELSO All ECLS Version1.1.pdf. 2009

11. Extracorporeal Life Support Organization (2009) ELSO patient specific guidelines. http://www.elso.med.umich.edu/WordForms/ELSO Pt Specific Guidelines.pdf. 2009

12. Graeme MacLaren Alain Combes Robert H. Bartlett. Contemporary extracorporeal membrane oxygenation for adult respiratory failure: life support in the new era. Intensive Care Med 38:210-220, DOI 10.1007/s00134-011-2439-2 2012

13. Van Meurs KP, Lally KP, Peek GJ, Zwischenberger JB (Eds) ECMO, Extracorporeal cardiopulmonary support in critical care, 3rd ed. Extracorporeal Life Support Organization, Ann Arbor, pp 203-215, 2005.

14. Madureira J, Lopes R, Rocha H, Morais C, Martins R, Silva A, Jardim M, Silva E, Pereira D, Santos P. ECMO (Extracorporeal membrane oxygenation) support in critically ill adult patients: is its use evidence driven? A meta-analysis http://medicina.med. up.pt/im/trabalhos_10_11/Sites/Turma9/downloads/articlepdf. pdf

15. Morris AH, Wallace CJ, Menlove RL, et al. Randomized clinical trial of pressure-controlled inverse ratio ventilation and extracorporeal $\mathrm{CO} 2$ removal for adult respiratory distress syndrome. Amer J Resp Crit Care Med 149:295-305, 2009.

16. Dietl CA, Wernly JA, Pett SB, et al. Extracorporeal membrane oxygenation support improves survival of patients with severe Hantavirus cardiopulmonary syndrome. $J$ Thorac Cardiovasc Surg 135(3): 579-84, 2008.

17. Turner DA, Williford WL, Peters MA, Thalman JJ, Shearer IR, Walczak RJ Jr, Griffs M, Olson SA, Sowers KW, Govert JA, Macintyre NR, Cheifetz IM. Development of a collaborative program to provide extracorporeal membrane oxygenation for adults with refractory hypoxemia within the framework of a pandemic. Pediatr Crit Care Med 12:426-430, 2011.

18. Scottish ECMO Expert Group http://www.scotland.gov.uk/ Resource/Doc/309738/0097693.pdf. 2009

19. Extracorporeal Life Support Organization H1N1 Registry. http://www.elso.med.umich.edu/H1N1Registry.html. 2010

20. Peek GJ, Mugford M, Tiruvoipati R, et al. Efficacy and economic assessment of conventional ventilatory support versus extracorporeal membrane oxygenation for severe adult respiratory failure (CESAR): a multicentre randomized controlled trial. Lancet 374 (9698): 1351-1363, 2009.

21. Extracorporeal membrane oxygenation (ECMO) for severe acute respiratory distress syndrome (SARS). ClinicalTrials.gov Identifier: NCT01470703, accessed-7/1/2014. 